\title{
CAPSULE COMMENTARIES \\ Capsule Commentary on Correa et al., Assessing the Effect of Clinical Inertia on Diabetes Outcomes: a Modeling Approach
}

\author{
Peter C. Smith, MD, MSC \\ Boston Medical Center and Boston University School of Medicine, Boston, MA, USA.
}

J Gen Intern Med 34(3):443

DOI: $10.1007 / \mathrm{s} 11606-018-4809-8$

() Society of General Internal Medicine 2019

I $\mathrm{n}$ this study, Correa et al. ${ }^{1}$ use a novel approach to shed new light on a familiar phenomenon-clinical inertia in the management of type 2 diabetes. Trials such as $\mathrm{UKPDS}^{2}$ have established that improved glycemic control can reduce the risk of diabetes complications. Similarly, observational studies have demonstrated that clinicians often fail to take advantage of opportunities to intensify therapy in patients with poor glycemic control, so-called clinical inertia. This research attempts to quantify the cost of these missed opportunities using a sophisticated type of computer simulation termed an agent-based model. ${ }^{3}$

Using their agent-based model, the authors simulate the lives of the populace of San Antonio, at least those aspects relevant to their endocrine and cardiovascular systems. Their digital Texans age 25 years, gain weight and lose it, quit smoking and then relapse, develop diabetes and, sometimes, succumb to its complications, while digital providers, sometimes, adjust their medication regimens. Then, with a key stroke, the providers get better, or worse, at promptly intensifying therapy in the face of hyperglycemia. The result: a 1year delay in response translates into an $8 \%$ increase in the incidence of neuropathy, $7 \%$ in retinopathy, $16 \%$ in nephropathy, and $25 \%$ in death from cardiovascular diseases, with some effects more pronounced in older, non-Hispanic White patients.
Obviously, there are some kinds of questions that a computer simulation cannot answer-it needs the results of realworld studies to define its parameters. We do not, however, have a magic wand that can, in real life, suddenly change the behavior of San Antonio's medical providers, which makes the question asked here an intriguing use of this new technology. And like other newly developed technologies, computer simulations can probably help to answer a lot of other previously unanswered questions. But like other new scientific tools, this one too needs to be carefully interrogated. Are race and ethnicity, for instance, simply modifiers of disease incidence or do they interact with clinician choice in a more complex way? Further research, in and out of the computer lab, is needed to answer this type of question.

Corresponding Author: Peter C. Smith, MD, MSc; Boston Medical Center and Boston University School of Medicine, Boston, MA, USA (e-mail: Peter.Smith@bmc.org).

Publisher's Note: Springer Nature remains neutral with regard to jurisdictional claims in published maps and institutional affiliations.

\section{REFERENCES}

1. Correa MF, Li Y, Kum H-C, Lawley MA. Assessing the Effect of Clinical Inertia on Diabetes Outcomes: A Modeling Approach. J Gen Intern Med https://doi.org/10.1007/s11606-018-4773-3

2. UK Prospective Diabetes Study (UKPDS) Group. Intensive blood-glucose control with sulphonylureas or insulin compared with conventional treatment and risk of complications in patients with type 2 diabetes (UKPDS 33). Lancet 1998;352(9131):837-853.

3. Li Y, Kong N, Lawley M, Weiss L, Pagán JA. Advancing the Use of Evidence-Based Decision-Making in Local Health Departments With Systems Science Methodologies. Am J Public Health 2015;105(S2):S217S222.

Published online January 4, 2019 